\title{
Doubts linger over America's top herbicide
}

Rex Dalton, Salt Lake City

Rising concerns about the environmental impact of the most widely used herbicide in the United States have led researchers to call for more time to study its effects before approval for the agent's use is renewed.

Researchers have until next February to submit their findings on the herbicide atrazine to the Environmental Protection Agency (EPA). The agency plans to complete its review of the chemical during 2003.

But at the annual meeting of the Society of Environmental Toxicology and Chemistry (SETAC) in Salt Lake City, Utah, this week, some scientists said that the necessary studies cannot be finished in time for the EPA's deadline.

Researchers in the field want to conduct a detailed study of what concentrations of atrazine cause environmental damage by disrupting the sexual development of amphibians, says Timothy Gross, an ecotoxicologist with the US Geological Survey in Gainesville, Florida.

Earlier this year, two studies indicated that

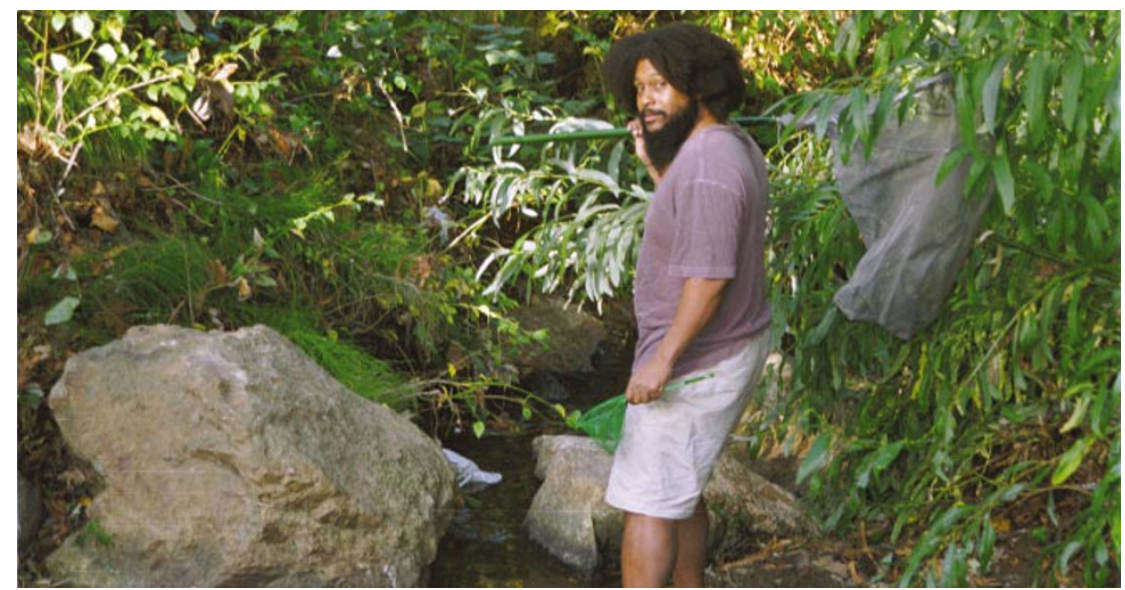

Tyrone Hayes suggests that reasonably low levels of atrazine can adversely affect frogs' development.

atrazine at levels as low as 0.1 parts per billion (p.p.b.) in water disrupted the sexual development of male frogs (T. Hayes et al. Proc. Natl. Acad. Sci. USA 99,5476-5480;2002 and T. Hayes etal. Nature 419, 895-896;2002).

But other scientists, including Gross, dis-

\section{Cambridge-MIT Institute probed}

\section{David Adam, London}

When the University of Cambridge, UK, and the Massachusetts Institute of Technology (MIT) announced plans for a collaborative institute (see Nature 402, 111; 1999), the move was hailed as a major step forward for both universities. But three years on, the Cambridge-MIT Institute (CMI) is seeking new leadership, amid scant evidence of its results and recurring questions about why it was set up in the first place.

Both executive directors of the institute, which has been promised up to $£ 68$ million (US\$108 million) in British government funds, are to step down in January. A spokesperson for the CMI says that Alan Windle, the Cambridge executive director, and John Vander Sande, MIT executive director, are leaving to concentrate on their research, and that both feel they have finished their jobs of setting up the partnership.

The institute was billed as an attempt to bolster Cambridge's exploitation of its research by creating spin-off firms and building partnerships with companies. It was also intended to organize student exchanges and training programmes for academics, and to fund collaborative research projects.

But the project has been dogged by controversy. Critics have even dubbed it the 'Cambridge Dome' - a reference to London's Millennium Dome, which was built at great public cost to little apparent purpose.
"This was a vast sum of money given without proper supervision, and there was really no clear idea what to spend it on," claims Gillian Evans, a history researcher at Cambridge who was a member of the university's governing council and a critic of the arrangement.

The British government has refused to confirm what the institute's \$14-million annual funding allocation is being spent on, saying that it is not free to do so until the CMI, which operates as a limited company, publishes its accounts.

But in a report published on 6 November, the House of Commons Science and Technology Committee describes the decision to fund the institute as "somewhat curious". Ian Gibson, chair of the committee, says that he plans to question science minister David Sainsbury about it later this month. "It seems a strange way for money to come out of the blue on a whim of somebody," Gibson says. Other universities were angered by the decision to allocate the money to Cambridge without giving them the opportunity to compete for the partnership.

But defenders of the CMI say that with MIT wanting to collaborate with Cambridge, an open competition would have been a waste of time. Although the institute got off to a slow start, Vander Sande says that several research projects, joint courses and student exchanges are now taking place. pute this, and have released unpublished results showing that much higher water concentrations of about 25 p.p.b. are needed to affect the frogs' sexual development. Government studies show that atrazine can be found at levels as high as 50 p.p.b. in US waters, and at even higher concentrations of several parts per million in agricultural run-off.

"The water is very muddy right now," says Gross, who also serves on a panel studying atrazine for Syngenta, the herbicide's Swissbased manufacturer. Syngenta wants the EPA to re-register atrazine for use in the United States. It has been banned in some European countries.

Gross' comments came after a spirited session at the SETAC meeting where academic and industry-backed scientists presented their findings on the impact of atrazine on wild and laboratory amphibians.

Tyrone Hayes - an evolutionary endocrinologist at the University of California, Berkeley, who is the lead author of the studies in Nature and the Proceedings of the National Academy of Sciences - was added at the last minute to the SETAC session, which already included prominent university scientists, such as James Carr of Texas Tech University in Lubbock, whose studies of atrazine are funded by Syngenta.

Once February's deadline is reached, the EPA will set up a scientific advisory panel to advise it on re-registering atrazine. A decision is expected next October.

But both Hayes and Gross say that a new study is needed to settle the debate, and that the February deadline won't allow this to happen. "We need a tie-breaker study," says Gross.

Thomas Steeger, an EPA biologist working on atrazine re-registration, says that the agency may be reluctant to extend the study deadline. But he adds that he wouldn't be surprised if the scientific advisory panel called for more study before issuing a recommendation on how the herbicide should be regulated. 